\title{
Study on Mine Rock Disaster Based on Acoustic Emission Technology
}

\author{
Yanbo Zhang ${ }^{1, a}$, Peng Liang ${ }^{1}$, Baozhu Tian ${ }^{1}$, Xiangxin Liu ${ }^{1}$ \\ ${ }^{1}$ School of Mining Engineering, Hebei United University, Tangshan 063009, China
}

\begin{abstract}
Study the effect of water on the acoustic emission quiet period before the destruction of rock based on the uniaxial loading experiment of acoustic emission of drying, natural and saturated basalt. The results show that the drying, natural and saturated basalt have AE quiet period before rupture. The load level of AE quiet period quiet period increase and shorter duration, and quiet period recognition is more difficult.AE quiet period, the $\mathrm{AE}$ event rate maintain per 10, but $\mathrm{AE}$ energy rate is not calm and characterized by accelerated release, and the release rate decreases with the increasing of water content. Due to full water characteristics of the actual mining basalt and the complexity of its fracture, the dominant frequency the $\mathrm{AE}$ rate of mutational characteristics and the $\mathrm{AE}$ event rate calm characteristic can be combined used to obtain information. The rate of mutation phenomenon before AE quiet period can be used as early warning information of saturated basalt rupture, and AE quiet period can be used as precursory information of saturated basalt rupture.
\end{abstract}

\section{INTRODUCTION}

A part of the strain energy is released in the form of elastic waves in rock failure, which is known as rock acoustic emission (acoustic emission, referred to as $\mathrm{AE}$ [1]. Rock acoustic emission quiet period refers to the phenomenon of $\mathrm{AE}$ that is seldom or difficult to observations before rock failure, and acoustic emission events rate is low in this period. Existing research shows that the acoustic emission quiet period can be used as important precursory phenomena of rock breaking, but due to the quiet period length is differ, it is not easy to identify. How to judge and identify true peace period before the damage is particularly important.

Many scholars have carried on the acoustic emission of rock loading process quiet period of experimental research, founding that and there are quiet period before the granite, sandstone and coal rock burst phenomenon, confirmed the rock acoustic emission in the stress in the process of its deformation quiet period [2-6]. Scholars have pointed out the sound emission of rock acoustic emission experiment quiet period the objective phenomenon, but the scholars study mainly for drying characteristic of sonic emission of rock under loading condition. Rock contains more water in the earth's crust, and the actual number of mine disasters is also associated with water. Therefore, the research on the rock failure process water acoustic emission characteristics influence is studied to guide the monitoring and early warning of actual mining rock disaster .

Through dry, natural and full of water basalt in uniaxial loading acoustic emission experiment, analysis acoustic emission quiet period of mechanical characteristics and parameters, looking for the three states

\footnotetext{
a Corresponding author: hnlp87@163.com
}

the difference of rock acoustic emission phenomenon of calm. Analysis water on rock acoustic emission quiet period the influence of the precursory characteristics, in order to explore the rock damage in different water cut conditions in the precursor, facilitate the application of field monitoring.

\section{The experiment process}

Basalt is typical of the hard rock, and widely exists in non-ferrous metals such as copper, tungsten and tin, which will produce a sudden violent damage under high stress, so the selection of basalt as experimental samples. The sample size is $50 \mathrm{~mm} \times 50 \mathrm{~mm} \times 100 \mathrm{~mm}$. Experimental design is dry, natural and full water three states, respectively to group $\mathrm{G}, \mathrm{Z}$ and $\mathrm{B}$, each set of 3 specimens. According to the relevant test specification requirements, the specimen of specific treatment method is as follows: (1) the dry state in the oven to $105^{\circ} \mathrm{C}$ drying $48 \mathrm{~h}$. (2) nature state: the specimen seal surface with plastic wrap, prevent moisture loss; (3) full water status: the specimen in the sink, water injection to the specimen height of first quarter, every $2 \mathrm{~h}$ after water injection to the specimen height, $1 / 2$ and $3 / 4$ respectively, total immersion specimen after $6 \mathrm{~h}$, timing is weighed, $48 \mathrm{~h}$ specimen free water in the water made full water sample.

TAW-3000 servo rock mechanics test system and PCI-2 acoustic emission monitoring system is used in the experiment. Experimental observation system is shown in figure 1. In order to ensure the specimen with the loading surface contact completely, avoiding contact with contact noise effects produced by acoustic emission monitoring results, first preload to $1.5 \mathrm{KN}$, then $0.2 \mathrm{~mm} / \mathrm{min}$ load to 
damage, mechanical and acoustic emission data synchronization records.

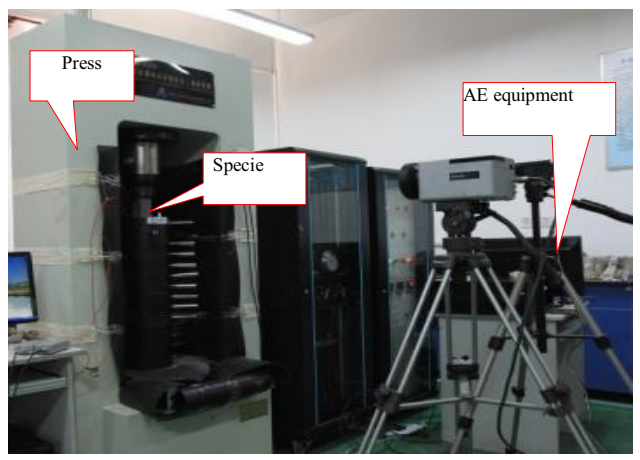

Fig.1 The experimental field

\section{AE quiet period characteristics of basalt}

\subsection{Load characteristics of basalt $A E$ quiet period.}

Figure 2 is the rate of acoustic emission events and time relation curve in the basalt rupture process. Can be seen from the diagram, drying, natural and full water three states of basalt, at the beginning of the loading pressure dense phase, there are a lot of acoustic emission, emerged the first peak rate of acoustic emission events. The elastic stage, the rate of acoustic emission events has a certain degree of decline. The inelastic phase, rate of acoustic emission events gradually raise with the increase of load level, to the second peak. After the front of the rock failure for a period of time, the rate of acoustic emission events suddenly plummeted, and maintain at the lower end, AE quiet period. Known from the analysis of the above, the whole process from acoustic emission events rate, drying, natural and full water basalt in acoustic emission phenomenon of calm before rupture. From the maximum rate of $\mathrm{AE}$ events and trends, along with the change of time drying, natural and full water basalt rate of acoustic emission events bimodality curve characteristics, quiet period after the second peak, and into the acoustic emission type belongs to the sudden quiet period. This approach creates basalt in the acoustic emission monitoring of quiet period the identification of precursory phenomena.

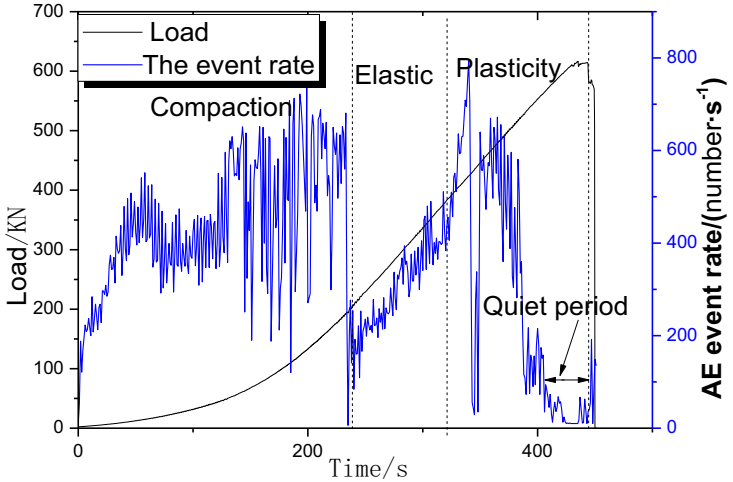

(1) Dry basalt

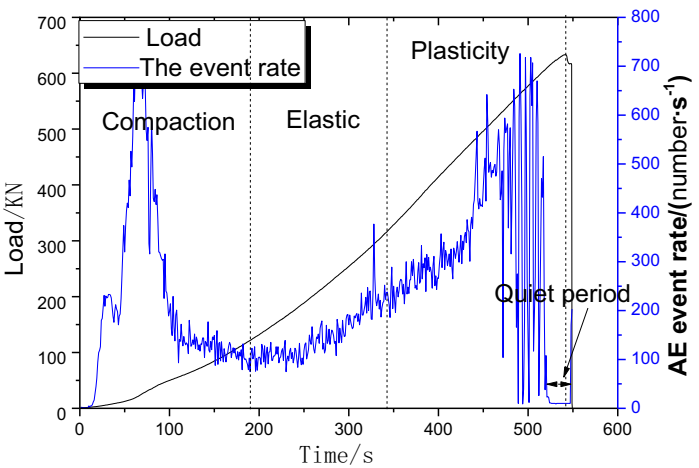

(2) Natural basalt

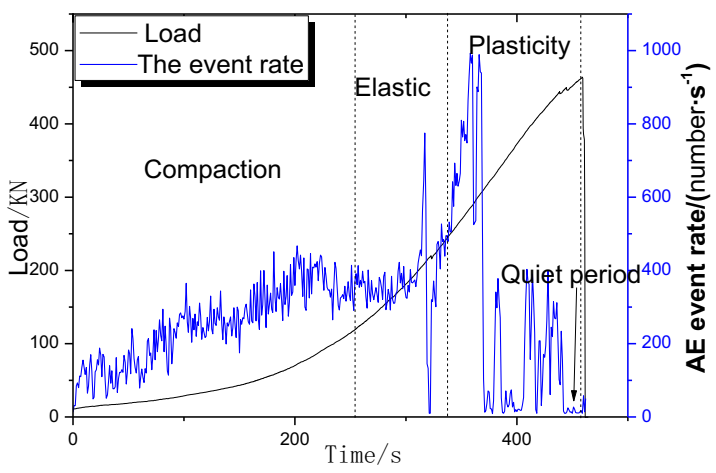

(3) Full water basalt

Fig.2 Relationship between load and AE events rate - time of basalt in the whole process of rupture

\subsection{Energy characteristics of basalt AE quiet period.}

Figure 3 is basalt rupture rate of acoustic emission events, AE energy rate and time relation curve of the whole process. Through statistics of the value of the rate of acoustic emission events after entering AE quiet period, discovering the value of the rate of acoustic emission events stay for 10 times per second. The quiet period for acoustic emission monitoring provides quantitative indicators, the recognition of acoustic emission phenomenon of quiet period. From the point of AE energy rate, the value of the three states basalt is low, later larger mutation appearing, as shown in figure 3 the B1 to B9. Peace in acoustic emission during the period, 
has a large capacity, as shown in figure 4 of the B3, B6 and B8, explaining calm period of acoustic emission events rate value is low, but AE energy rate is not calm, shows the accelerated release characteristics, occurrence rate of acoustic emission events "calm" and acoustic emission energy "not calm" phenomenon. Therefore, the accelerate release of $\mathrm{AE}$ energy rate is significant for instability of rock damage prediction.

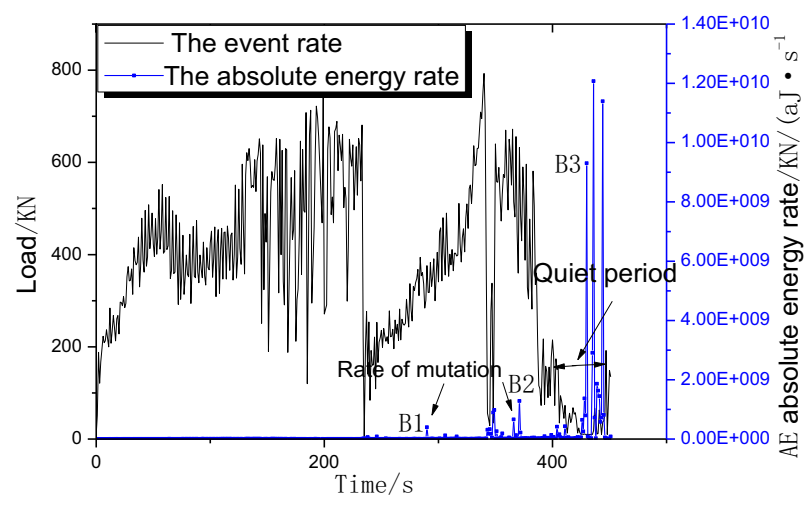

(1) Dry basalt

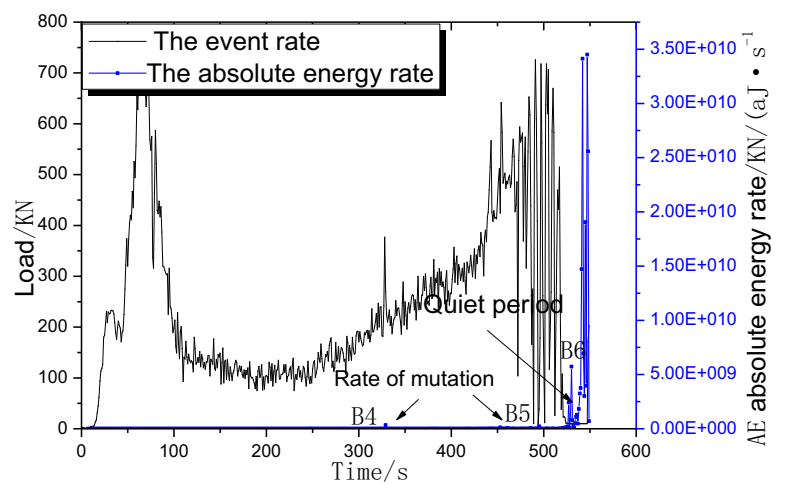

(2) Natural basalt

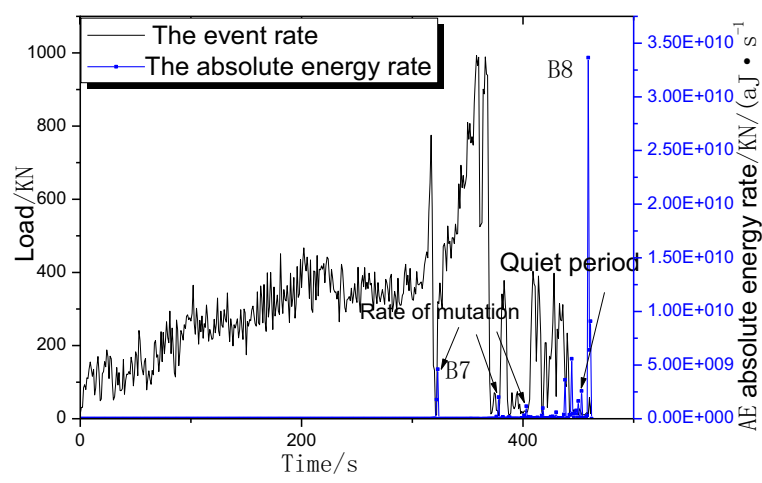

(3) Full water basalt

Fig.3 Relationship between $\mathrm{AE}$ events rate and $\mathrm{AE}$ energy ratetime of basalt in the whole process of rupture

\subsection{Comprehensive analysis.}

Acoustic emission quiet period of load level, AE quiet period duration and AE quiet period average energy rate are counted. Results are shown in table $1, \sigma \mathrm{c}$ is peak load for rock burst. Analysis can be seen that the load level of dry, natural and full water basalt getting into AE quiet period is $0.86 \sigma \mathrm{c}$ and $0.94 \sigma \mathrm{c}$ and $0.97 \sigma \mathrm{c}$, showing that load level getting into AE quiet period increases with the increase of water content. Dry, natural and full water basalt $\mathrm{AE}$ quiet period lasted longer than $9.26 \%, 3.28 \%$ and $2.77 \%$ respectively, showing basalt $\mathrm{AE}$ quiet period lasted longer than and decreased with the increase of water content, namely the basalt moisture content, the greater the duration of the acoustic emission quiet period shorter. With the increase of water content, releasing energy value decrease. From acoustic emission to analyze big capacity corresponding to rock burst, drying, natural and full water basalt before entering the $\mathrm{AE}$ quiet period there has been big rupture, internal damage is more severe. Based on the previous analysis, water content is big, the load level into the $\mathrm{AE}$ quiet period is higher, and duration of the acoustic emission quiet period is shorter. Therefore, the water saturated basalt $\mathrm{AE}$ quiet period, has the certain difficulty in recognition. But the actual mining basalt is in water saturated state, in the actual application, acoustic emission energy before the quiet period mutation phenomenon can serve as an early warning information saturated basalt early, AE quiet period can be used as water saturated basalt precursory information.

Table1 Statistics of load and time of basalt in acoustic emission quiet period

\begin{tabular}{cccc}
\hline state & $\begin{array}{c}\text { AE quiet period } \\
\text { average energy } \\
\text { rate } / 10^{9}\left(\mathrm{aJ}^{-1} \mathrm{~s}^{-1}\right)\end{array}$ & $\begin{array}{c}\text { AE quiet period } \\
\text { load levels(Peak } \\
\left.\text { load } \sigma_{\mathrm{c}}\right)\end{array}$ & $\begin{array}{c}\text { AE quiet } \\
\text { period } \\
\text { duration }\end{array}$ \\
\hline dry & 2.9133 & $0.86 \sigma \mathrm{c}$ & $9.26 \%$ \\
$\begin{array}{c}\text { natural } \\
\text { Full of } \\
\text { water }\end{array}$ & 2.0333 & $0.94 \sigma \mathrm{c}$ & $3.28 \%$ \\
\hline
\end{tabular}

\section{Conclusions}

(1) Drying, natural and full water basalt has acoustic emission quiet period before fracture, but different property, different characteristics of acoustic emission quiet period. On the basis of the understanding of rock property, at the same time, combined with acoustic emission calm the precursory characteristics, it is more significance for mine rock (body) instability damage acoustic emission monitoring and early warning.

(2) The drying rate, natural and full water basalt acoustic emission events characterized by bimodality curve characteristics, quiet period occurred after the second peak, and into the acoustic emission type belongs to the sudden quiet period. This benefit basalt fracture identification of calm period precursory phenomena in acoustic emission monitoring.

(3) Drying, natural and full water basalt $\mathrm{AE}$ quiet period, rate of acoustic emission events is calm, value maintained at 10 times per second. Acoustic emission energy is not calm, showing the accelerated release characteristics, releasing energy value decreased with the increase of water content.

(4) For drying, natural and full water basalt, with the increase of water content, AE quiet period load levels, 
quiet period duration. Therefore, for full water basalt $\mathrm{AE}$ quiet period, should be combined with the acoustic emission energy, identify them effectively.

(5) Due to the actual full water characteristics of basalt in mines, and the complexity of its fracture, in the actual application, the energy mutation features and event rate of calm can be combined. Electrical mutation phenomenon can be used as a full water basalt early warning information, acoustic emission quiet period can be a full water basalt burst precursor information.

\section{Acknowledgements}

The national natural science foundation of China(51374088,51174071), the natural science foundation of Hebei Province(E2012209047).

\section{references}

1. LOCKNER D A: International Journal of Rock Mechanics and Mining Sciences and Geomechanics Abstracts, 1993, 30(7):883-899.

2. Xiangang Yin, Shulin LI, Haiyan Tang, Jianliang Pei: Chinese Journal of Rock Mechanics and Engineering, 2009,S2:3383-3390.(In Chinese)

3. Jianpo Liu, Shida Xu, Yuanhui Li, Long Bing Dong, Jiong Wei: Chinese Journal of Rock Mechanics and Engineering,2012,12:2538-2547. (In Chinese)

4. Xingdong Zhao, Chunan Tang, Yuanhui Li, et al: Chinese Journal of Rock Mechanics and Engineering, 2006,25(Supp.2):3673-3678. (In Chinese)

5. Dongqiang $\mathrm{Xu}$, Changda Zhou, Zhaoyong $\mathrm{Xu}$ : Journal of Seismological Research, 1994, 17(8): 802807. (In Chinese)

6. Shugang Cao, Yanbao Liu, Liqiang Zhang: Chinese Journal of Rock Mechanics and Engineering, 2007, 26(Supp.1):2794-2799. (In Chinese)

7. Shiyu Li, Taiming He, Xiangchu Yin, et al: Introduction to rock fracture mechanics [M]. Hefei: University of Science and Technology of China, 2010:282-283. (In Chinese)

8. Chunliang Zhang, Wieczorek K, Xie M L. Journal of Rock Mechanics \& Geotechnical Engineering, 2010, 2(1):41-47. (In Chinese)

9. Qingqing Jiang, Jiangteng Li, Yifu Hu, et al: Rock and Soil Mechanics,2008,29(9):2527-2530. (In Chinese)

10. Ping Cao, Hui Yang, Xueliang Jiang: Journal of Central South University: Science and Technology, 2010,42(2):649-654. (In Chinese)

11. Shulin Li, Xiangang Yin, Yongjia Wang, et al: Chinese Journal of Rock Mechanics and Engineering, 2004,23(15):2499-2503. (In Chinese)

12. Shuheng Tang, Zhifeng Yan, Baocun Zhu, et al: Acoustic emission characteristics of water-saturated coals in uniaxial compression experiment[J]. Journal of China Coal Society, 2010, 35(1): 37-41. (In Chinese) 